\title{
Giant impacts and the initiation of plate tectonics on terrestrial planets
}

\author{
Javier Ruiz \\ Departamento de Geodinámica, Facultad de Ciencias Geológicas, Universidad Complutense de Madrid, 28040 Madrid, Spain
}

Keywords:

Plate tectonics

Mantle convection

Giant impacts

Lithosphere

Stagnant lid

\begin{abstract}
A B S T R A C T
Earth is the only terrestrial planet with present-day lithosphere recycling through plate tectonics. However, theoretical models of mantle convection based on general considerations find that all the terrestrial planets should be operating in the stagnant lid regime, in which the planets are one-plated and there is no lithosphere recycling. The stagnant lid regime is a consequence of the strong viscosity contrast across the convective layer, and therefore the upper lid (roughly equivalent to the lithosphere) must be sufficiently weakened in order to be mobilized. Here I propose that giant impacts could have provided the upper layer weakening required for surface recycling, and hence for plate tectonics, to initiate on the early Earth. Additionally, giant impacts originated lithosphere thickness and density differences, which might contribute to the initiation of subduction. Impacts are more energetic for Earth than for Mars, which could explain the likely early existence of plate tectonics on the Earth whereas Mars never had lithosphere recycling. On the other hand, convection on Mercury and the Moon might be sluggish or even inexistent, implying a reduced influence of giant impacts on their internal dynamics, whereas there is no record of the earliest geological history of Venus, which obscures any discussion on the influence of giant impacts on their internal dynamics.
\end{abstract}

\section{Introduction}

Plate tectonics characterizes the geodynamic behavior of the present-day Earth, and there are evidences suggesting that it was active since at least 3-3.5 Ga (Cawood et al., 2006; Moyen et al., 2006; Chen et al., 2009; Hastie et al., 2010), and maybe more than $4 \mathrm{Ga}$ (Hopkins et al., 2008); although other authors consider that plate tectonics would have started later, around $\sim 2.0 \mathrm{Ga}$ (Hamilton, 2003; Thompson et al., 2010). Also, terrestrial plate tectonics, defined greatly by both subduction and mid-ocean ridge spreading, is unique among the planetary bodies of the Solar System.

The terrestrial planets Mercury and the Moon (here the extended terminology that consider the Moon as a terrestrial planet has been followed) have been one-plate planets throughout their evolutionary history (e.g., Taylor and McLennan, 2009; Watters and Schultz, 2010). Some authors suggested that Mars experienced an early phase of plate tectonics, in order to explain the differences in topography and surface age between the smooth northern plains and the highly cratered southern highlands of this planet (Sleep, 1994; Connerney et al., 1999; Fairén et al., 2002). However, high-resolution topography and radar sounding have revealed a large population of buried impact basins in Mars, implying a similar (and very early, >4 Ga) age of the basement throughout the entire planet (Frey, 2006; Watters et al., 2006). Thus, currently there is no evidence supporting an ancient phase of plate tectonics in Mars. After the more extended vision, the average age of the surface of Venus is 0.5-1 Ga (e.g., McKinnon et al., 1997) hindering the knowledge of the early dynamics of this planet, which does not show evidences of recent plate tectonics (McGill et al., 2010). Recently Hansen and López (2010) have suggested that detailed regional mapping indicates a geological record temporally deeper than previously thought for Venus, but there is no evidence indicating ancient plate tectonics.

The best analogs for plate tectonics come from the outer Solar System. The icy satellite Europa shows regions where the crust has been separated away and the gap filled with new material arising from the interior (Sullivan et al., 1998). Some of these regions display structures and morphologies typical of terrestrial mid-ocean ridges (Prockter et al., 2002), which is also applicable to the "tiger stripes" on the South Polar Terrain of Enceladus (see www.nasa.gov/mission_pages/cassini/multimedia/pia11138.html). However, there is nothing similar to subduction zones in Europa or Enceladus. Otherwise, processes of crustal destruction on Europa have been deduced to have occurred in bands of unusual aspect (e.g., Greenberg, 2004), and scattered crustal destruction seems also recorded in extensional regions (Mével and Mercier, 2005). So, although structures apparently equivalent of mid-ocean spreading exist in icy satellites, there is no equivalent for terrestrial subduction and plate tectonics on other planetary bodies.

Precisely, the initiation of subduction is the key point for the understanding of the terrestrial plate tectonics. Indeed, slab pull is the main force acting on ocean plates, and it drives the movement of these plates (e.g., Chapple and Tullis, 1977). But current plate 
tectonic could be considered a self-sustaining process, which does not give direct information on its own initiation. Theoretical models and numerical analysis of thermal convection in the mantle (for a review of mantle convection see Schubert et al., 2001) find that for large vertical viscosity contrasts across the convective layer, as usually corresponds to realistic temperaturedependent rock rheologies, a cold and essentially immobile lid develops above the actively convective system. This "stagnant lid" regime correspond to one-plate planets, but obviously it is not the case for the Earth. On the other hand, convection including surface movement and recycling is obtained only if the viscosity contrast across the layer is small. Moreover, plate tectonics is not simply convection with surface recycling, since subduction is an asymmetric downwelling process implying the descent of only one plate, while thermal convection usually supposes the sinking of both convergent upper boundary layers (e.g., Bercovici, 2003). The proper initiation of subduction is a very difficult process to be theoretically explained (Mueller and Phillips, 1991; Toth and Gurniss, 1998). Indeed, numerous hypotheses have been proposed to explain the origin of subduction and plate tectonics in the Earth (see Nikolaeva et al., 2010), but a clear advance on this problem has not been obtained. Thus, the generation of terrestrial plate tectonics is a major geodynamic problem (Bercovici, 2003).

Hansen (2007) proposed that large asteroidal impacts on cylindrical mantle upwellings could induce crustal rifting and spreading, with the formation of new crust, which would be subducted in the boundary between the previous crust with normal thickness and the thinned crust in the basin formed by the impact. The interest of the last hypothesis is the suggestion of an extraterrestrial cause for the initiation of plate tectonics in the Earth, although very specific circumstances are required for this triggering mechanism to operate. In any case, giant impacts are a powerful mechanism for fracturing the lithosphere and originate significant variations of crustal and lithosphere thickness and density, which could be important in order to facilitate subduction initiation. In this paper I propose that giant impacts may have been a key factor for weakening the early terrestrial lithosphere, whereas this mechanism was less efficient for Mars, maybe explaining the differences in tectonic style between those two planets in a simply way. The case for Venus is not discussed extensively, since there is no record of the early dynamics of this planet, neither for Mercury nor the Moon, where mantle convection might have been much limited. Also, the case of icy satellites is not been considered here, since their physical and chemical nature, as well as orbital histories (which determine their thermal histories), are very different to those of the terrestrial planets.

\section{The stiffness and thickness variations of the lithosphere}

After theoretical analyses, mantle convection should be operating in the stagnant lid regime in all the terrestrial planets (e.g., Solomatov and Moresi, 1997). As a consequence, in order to have surface recycling in a terrestrial planet, the effective viscosity of the upper lid must be reduced in any way, in order in turn to reduce the total viscosity contrast across the layer and permit lid mobilization (e.g., Solomatov, 2004). In this sense, the presence of water is frequently considered to be an important factor for contributing to the initiation of plate tectonics (e.g., RegenauerLieb et al., 2001; Solomatov, 2004), since it reduces lithospheric effective viscosity and rock strength. However, the strong temperature-dependence of rocks, which causes the relative viscosity contrast through the convective layer, also works for wet rheologies. So, at least another factor is needed in order to weaken the lithosphere and to permit the initiation of plate tectonics
By assuming a pre-fractured brittle upper layer, convection with upper lid recycling can be obtained (e.g., Moresi and Solomatov, 1998; Solomatov, 2004). Similarly, numerical modeling suggests that pre-existent faults would permit subduction initiation with terrestrial reasonable parameters (Toth and Gurniss, 1998). The fracturing required by these models is equivalent to that used for the calculation of brittle strength in the construction of strength envelopes (i.e., the existence of preexistent faults in all orientations without specifying penetration; e.g., Ranalli, 1997). But a problem persists: on Earth the majority of tectonic deformation (including large faults) is in fact related to plate tectonics (see, for example, Kearey et al., 2008), which would leave open the problem of generating lithosphere recycling on the Earth from mantle convection.

Faulting on the one-plate planets Mars, Mercury and the Moon is less pervasive than on the Earth. Faulting on Mars, although significant, is less extensive than on Earth, and mostly related to the building of Tharsis, a massive magmatic rise covering about one-fourth of the Martian surface (Anderson et al., 2001; Dohm et al., 2001). The tectonics of Mercury is dominated by contractional faults related to planetary cooling (Watters et al., 2009), whereas faulting on the Moon is very limited (see Watters and Johnson, 2010). On the other hand, tectonics and faulting on Venus is extensive (McGill et al., 2010), but their global dynamics is poorly understood. Also, Venus is heavily dehydrated due to an extremely strong greenhouse, which increases the strength of the lithosphere (e.g., Mackwell et al., 1998), and may play a role in the current absence of plate tectonics in this planet. In fact, Venus could have experienced one (or several) phase of crustal recycling (e.g., Turcotte, 1993; Romeo and Turcotte, 2008), but it is unclear as the observed tectonics deformation is related to the dynamics that existed in the times for which a geological record is inexistent.

Thus, in view of the known examples of preservation of very ancient crusts, the faulting required to overcome the stiffness of the upper lid, necessary for initiate lid mobilization and recycling, could not be produced related to the interior planetary dynamics. The origin of this pre-fracturing therefore constitutes another significant problem related to the origin of plate tectonics, since it remains to be explained.

Another key point is the role of crustal and lithospheric thickness variations in the generation of plate tectonics. A recent numerical work (Nikolaeva et al., 2010) suggests that subduction initiation in terrestrial passive margins would be favored for a thinned and heated chemically buoyant continental lithosphere, whereas the influence of the age of the oceanic lithosphere (i.e., thermal subsidence) is secondary, contrarily to the usual expectations (e.g., Vlaar and Wortel, 1976). Interestingly, Burov and Cloetingh (2010) have recently proposed initiation of subduction related to upper mantle plumes and lithosphere thinning in continental regions. It would therefore be interesting to consider a mechanism capable of simultaneously fracturing the lithosphere and create crustal and lithospheric thickness variations previously to the onset of plate tectonics.

\section{The influence of giant impacts}

As above summarized, initiation of lithosphere mobility and recycling requires a relatively low lithosphere viscosity, and initiation of subduction sensu stricto could additionally require pre-existent large faults and possibly a locally thin lithosphere. Precisely, giant impacts (here defined as impacts originating impact structures thousands of kilometers across) are a powerful mechanism for fracturing the lithosphere, as well as for creating differences in density, and in crustal and lithosphere thickness. 
Geophysical surveys of terrestrial impact structures have shown that outward from the crater and the brecciated zone directly below, a region of cracked and fractured country rock exists, which reach depths larger than the structure radius (Innes, 1961; Ahrens et al., 2002). Thus, it is obvious that giant impacts pervasively fractured at least a substantial portion of the lithosphere (furthermore at a time when the lithosphere was thinner), which, as discussed in the previous section, would be sufficient to create a pre-fractured brittle lithosphere, and hence a permit lithospheric recycling after theoretical models (Moresi and Solomatov, 1998; Solomatov, 2004).

Giant impacts in fact occurred in the early Solar System. Cratering was very intense until $\sim 3.8 \mathrm{Ga}$ (e.g., Strom et al., 2005), a similar time to that proposed for the start of plate tectonics on the Earth for several studies (e.g., Hopkins et al., 2008; Chen et al., 2009; Hastie et al., 2010). Giant impacts occurred during this heavy bombardment created the very large impact basins currently visible on the surfaces of Mars, Mercury and the Moon; equivalent giant basins would have been removed from the surfaces of Venus and the Earth by both endogenic and exogenic processes.

Giant impacts are also capable of producing contrasts in lithosphere thickness. Thinning of the crust by giant impacts is very notorious in crustal thickness maps of the Moon and Mars (Zuber et al., 1994; Neumann et al., 2004). Indeed, in these planets crustal thickness below large impact basins can even be a small fraction of the original crustal thickness. Simultaneously, the crust around giant impact basins is thickened due to the formation of ejecta blanket, further increasing thickness contrasts; on Mars this is clear in the annulus of thick crust around Hellas and Utopia basins (see Neumann et al., 2004). Crustal thickness variations are in turn related to variations in the rheology and thermal state of the lithosphere (e.g., Ranalli, 1997; Stüwe, 2007; Ruiz et al., 2008). For example, the thermal conductivity of crustal materials is lower than in mantle materials (e.g., Clauser and Huenges, 1995), for this reason, a lithosphere with a relatively thicker crust has higher deep temperatures, which reduces the lithosphere thickness and, therefore, the mantle lithosphere thickness. Also, a thick crust coupled with a thin mantle lithosphere implies in turn a less dense lithosphere.

\section{Discussion}

Giant impacts could create conditions favoring lithosphere mobility and recycling in terrestrial planets. But, how would they affect the lithospheric dynamics in each particular case? This depends on both the magnitude of the disruption due to giant impacts and the previous convective dynamics of the impacted planet.

Mercury and the Moon are small planetary bodies with relatively limited activity throughout the history of the Solar System. Precisely due to their small size, mantle convection in these bodies have been sluggish or even inexistent (Breuer et al., 2007; Gohds and Arkani-Hamed, 2007; Williams et al., 2011), and it is therefore unlikely that weakening by giant impacts favor upper lid recycling. Mars is an intermediate-size terrestrial planet recording an ancient significant magmatic and tectonic activity (e.g., Head et al., 2001; Anderson et al., 2001), and for this reason Mars was a better candidate to have experienced an early plate tectonics. The early $(\sim 3.5-4 \mathrm{Ga})$ dynamics of Venus is unknown, and there is no way to know if giant impact had any influence on its style of mantle convection. Thus, here we discuss mainly the cases of Earth and Mars.

The impact structure size, and hence cratering fracturing and disruption, is proportional to the kinetic energy of the impactor (for a review of impact processes see de Pater and Lissauer, 2010), which is the sum of (1) the kinetic energy at the planet surface consequence of the acceleration due to the planet's gravity (which is equal to the escape velocity from the planet), and (2) the kinetic energy due to the initial relative velocity with respect to the planet (i.e., the relative velocity of the impactor far the impacted planet). On the other hand, absolute (and relative) velocities of planetesimal bodies collisioning in the early Solar System are unknown, but in general, they would be (according to Kepler's laws) comparable to the orbital velocity of each planet. The initial relative velocity for a prograde planetesimal should be, at most, similar to the orbital velocity of each planet, and could have been much lower. Average initial relative velocities must have been around half of the orbital velocity. Indeed, asteroids collisioning with the Earth-Moon system have an initial relative velocity of $\sim 16 \mathrm{~km} \mathrm{~s}^{-1}$ (Chyba, 1991), value roughly similar to $14.9 \mathrm{~km} \mathrm{~s}^{-1}$, the half of the average orbital velocity of the Earth.

Fig. 1 shows kinetic energy per unit mass of impactors on Earth and Mars, as a function of their initial velocities. The higher kinetic energy of the collisions on the Earth implies a higher energy available for lithospheric disruption (and therefore weakening) than for Mars. So, the higher weakening of the early Earth's lithosphere could have favored the initiation of plate tectonics, whereas the lower weakening experienced for Mars lithosphere could have not been sufficient to initiate lithosphere recycling. Giant impacts could therefore be important to determine the mode of convection of terrestrial planets, as well as to explain in a simple way the reason why plate tectonics started in the Earth but not in Mars.

Venus has an Earth-like size and mass, but a higher orbital velocity. This suggests that giant impacts should have been proportionally more energetic than on our planet. If effectively giant impacts had a role in determining the style of mantle convection in terrestrial planets, then Venus is a good candidate to have experienced some kind of lithospheric recycling in the past. In this case, cessation of lithospheric mobility could be related to the extreme dehydration suffered by this planet.

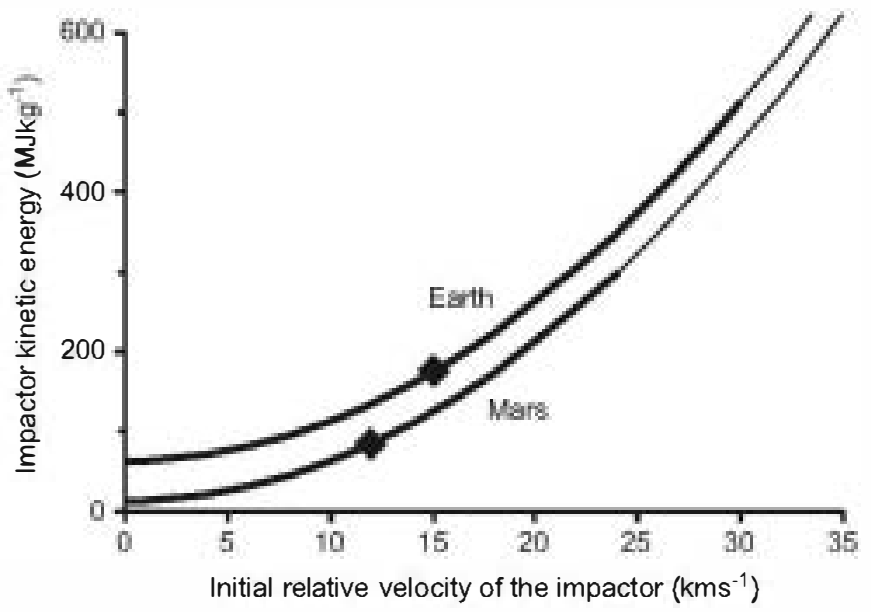

Fig. 1. Kinetic energy per unit mass of impactors on the surface of Earth and Mars, as a function of the initial relative velocity (the relative velocity far the planet) of the impactors; kinetic energy per unit mass is calculated from $\left(v_{e}^{2}+v_{i}^{2}\right) / 2$ where $v_{e}$ and $v_{i}$ are, respectively, the escape velocity and the initial relative velocity. Thick portions of the curves indicate the possible range of relative impact velocities for asteroidal impactors, whereas diamonds indicate mean impact velocities. For zero initial relative orbital velocity, the kinetic energy of the impactor is only due to the velocity acquired through gravity acceleration caused by the impacted planet; this velocity is equal to the escape velocity from the planet surface: 11.19 and $5.03 \mathrm{~km} \mathrm{~s}^{1}$ for Earth and Mars, respectively. 


\section{Conclusions}

Giant impacts on the early Earth could have provided the upper layer weakening (through fracturing) required for surface recycling, and hence for plate tectonics to initiate. Impact fracturing would be more decisive due to the higher gravity of the Earth, which would imply a higher lithospheric strength (and hence a higher effective viscosity) in absence of cratering weakening. This could explain the reason why Earth has plate tectonics whereas Mars never had lithosphere recycling. Giant impacts also might contribute to the initiation of subduction through originating large faults, lithosphere thickness and density differences, whose magnitude would be again depending on the kinetic energy of the impact process and therefore on planetary gravity and relative orbital velocity, both higher for Earth than for Mars. In a similar way, large impacts have been proposed to cause major geodynamic and magmatic episodes on the Earth (see Glikson, 2008, and references therein), including mid-ocean spreading, rifting initiation and continental breakup (Glikson, 1999, Hansen, 2007).

Thus, exogenic and historical factors, such as the availability and size of potential impactors in different regions of the early Solar System, might contribute to determine the convective regime of the terrestrial planets. This does not constitute a surprise, since impact have strongly influenced the formational, rotational, geological, atmospheric (and biological in the case of the Earth) properties and evolution of planetary bodies (e.g., de Pater and Lissauer, 2010; Grieve et al., 2007). Some of these properties in turn influence climate history, highlighting the role of impact in planetary evolution. Future modeling could contribute to determine if giant impacts, besides general upper lid weakening, are capable of favoring lithosphere failure and subduction.

\section{Acknowledgments}

The author thanks the comments of three anonymous reviewers, Cesar Casquet and the members of the Grupo de Ciencias Planetarias de Madrid. This work was supported by a contract Ramón y Cajal co-financed from the Ministerio de Ciencia e Innovación of Spain and the Fondo Social Europeo (ESF).

\section{References}

Ahrens, T.J., Xia, K., Coker, D., 2002. Depht of cracking beneath impact craters: new constraint for impact velocity. In: Furnish, M.D., Thadhani, N.N., Horie, Y. (Eds.), Shock-Compression of Condensed Matter. American Institute of Physics, New York, pp. 1393-1396.

Anderson, RC., Dohm, J.M., Golombek, M.P., Haldemann, A., Franklin, B.J., Tanaka, K.L., Lias, J., Peer, B., 2001. Significant centers of tectonic activity through time for the western hemisphere of Mars. J. Geophys. Res. 106, 20,563-20, 585.

Bercovici, D., 2003. The generation of plate tectonics from mantle convection. Earth Planet. Sci. Lett. 205, 107-121.

Breuer, D., Hauck, S.A., Buske, M., Pauer, M., Spohn, T., 2007. Interior evolution of Mercury. Space Sci. Rev. 132, 229-260.

Burov, E., Cloetingh, S., 2010. Plume-like upper mantle-instabilities drive subducion initiation. Geophys. Res. Lett. 37. doi:10.1029/2009GL041535.

Cawood, P.A., Kröner, A., Pisarevsky, S., 2006. Precambrian plate tectonics: criteria and evidence. GSA Today 16 (7), 4-11.

Chyba, C.F., 1991. Terrestrial mantle siderophiles and the lunar impact record. Icarus 92, 217-233.

Chapple, W.M., Tullis, T.E., 1977. Evaluation of the forces that drive the plates. J. Geophys. Res. 82, 1967-1984.

Chen, C.-W., Rondenay, S., Evans, R., Snyder, D.B., 2009. Geophysical detecrion of relict metasomatism from an Archean $(\sim 3.5 \mathrm{Ga})$ subduction zone. Science 326, 1089-1091.

Clauser, C., Huenges, E., 1995. Thermal conductivity of rocks and minerals. In: Ahrens, T.J. (Ed.), Rock Physics and Phase Relations: A Handbook of Physical Constants. AGU Reference Shelf 3. American Geophysical Union, Washington, D.C, pp. $105-126$.
Connerney, J.E.P., Acuña, M.H., Wasilewski, P.J., Ness, N.F., Rème, H., Mazelle, C. Vignes, D., Lin, R.P., Mitchell, D.L., Cloutier, P.A., 1999. Magnetic lineations in the ancient crust of Mars. Science 284, 794-798.

de Pater, I., Lissauer, J.J., 2010. Planetary Sciences, second ed. Cambridge University Press, Cambridge 647pp.

Dohm, J.M., Ferris, J.C., Baker, V.R, Anderson, R., Hare, T.M., Strom, R. G., Barlow, N.G. Tanaka, K.L., Klemaszewski, J.E., Scott, D.H., 2001. Ancient drainage basin of the Tharsis region, Mars: potential source for outflow channel systems and putative oceans or paleolakes. J. Geophys. Res. 106, 32,943-32,958.

Fairén, A.G., Ruiz, J., Anguita, F., 2002. An origin for the linear magnetic anomalies on Mars through accretion of terranes: implications for dynamo timing. Icarus $160,220-223$.

Frey, H.V., 2006. Impact constraints on, and a chronology for, major events in early Mars history. J. Geophys. Res. 111, E08S91. doi: 10.1029/2005JE002449.

Gohds, A., Arkani-Hamed, J., 2007. Impact-induced convection as the main mechanism for formation of lunar mare basalts. J. Geophys. Res. 112, E03005. doi:10.1029/ 2006JE002709.

Glikson, A.Y., 1999. Oceanic mega-impacts and crustal evolution. Geology 27, 387-390.

Glikson, A.Y., 2008. Field evidence of Eros-scale asteroids and impact-forcing of Precambrian geodynamic episodes, Kaapvaal (South Africa) and Pilbara (Western Australia) Cratons. Earth Planet. Sci. Lett. 267, 558-570.

Greenberg, R, 2004. The evil twin of Agenor: tectonic convergence on Europa. Icarus $167,313-319$

Grieve, R.A.F., Cintala, M.J., Tagle, R, 2007. Planetary impacts. In: McFadden, L.A., Weissman, P.R, Johnson, T.V. (Eds.), Encyclopedia of the Solar System second ed. Academic Press, San Diego, pp. 813-828

Hamilton, W.B., 2003. An alternative earth. GSA Today 13, 4-12

Hansen, V.L, 2007. Subduction origin on early Earth: a hypothesis. Geology 35 , 1059-1062.

Hansen, V.L., López, I., 2010. Venus records a rich early history. Geology 38, $311-312$

Hastie, A.R, Kerr, A.C., McDonalds, I., Mitchell, S.F., Pearce, J.A., Wolstencroft, M., Millar, I.L., 2010. Do Cenozoic analogues support a plate tectonic origin for Earth's earliest continental crust. Geology 38, 495-498.

Head, J.W., Greeley, R, Golombek, M.P., Hartmann, W.K., Hauer, E., Jaumann, R, Masson, P., Neukum, G., Nyquist, L.E., Carr, M.H., 2001. Geological processes and evolution. Space Sci. Rev. 96, 263-292.

Hopkins, M., Harrison, T.M., manning, C.E., 2008. Low heat flow inferred from $>4 \mathrm{Gyr}$ zircons suggests Hadean plate boundary interactions. Nature 456 493-496.

Innes, M.J.S., 1961. The use of gravity methods to study the underground structure and impact energy of meteorite craters. J. Geophys. Res. 66, 2225-2239.

Kearey, P., Klepeis, K.A., Vine, F.J., 2008. Global Tectonics third ed. Wiley-Blackwell, exford 482pp.

Mackwell, S.J., Zimmerman, M.E., Kohlstedt, D.L, 1998. High-temperature deformation of dry diabase with application to tectonics on Venus. J. Geophys. Res. $103,975-984$.

McGill, G.E., Stofan, E.R, Smrekar, S.E., 2010. Venus tectonics. In: Watters, T.R, Schultz, RA. (Eds.), Planetary Tectonics. Cambridge University Press, Cambridge, pp. 81-120.

McKinnon, W.B., Zhanle, K.J., Ivanov, B.A., Melosh, J.H., 1997. In: Bougher, S.W., Hunten, D.M., Phillips, RJ. (Eds.), Cratering on Venus: Models and observations.. Venus II. University of Arizona Press, Tucson, pp. 969-1014.

Mével, L., Mercier, L, 2005. Resorption process in Astypalaea Linea extensive region (Europa). Planet Space Sci. 2005, 771-779.

Moresi, L.N., Solomatov, V., 1998. Mantle convection with a brittle lithosphere: thoughts on the global tectonic styles of the Earth and Venus. Geophys. J. Int. 133, 669-682.

Moyen, J.F., Stevens, G., Kisters, A., 2006. Record of mid-Archaean subduction from metamoephism in the Barbeton terrain, South Africa. Nature 442, 559-562.

Mueller, S., Phillips, RJ., 1991. On the initiation of subduction. J. Geophys. Res. 96, 651-665.

Neumann, G.A., Zuber, M.T., Wieczorek, M.A., McGovern, P.J., Lemoine, F.G., Smith D.E., 2004. The crustal structure of Mars from gravity and topography. J. Geophys. Res. 109, E08002. doi:10.1029/2004JE002262.

Nikolaeva, K., Gerya, T.V., Marques, F.๑., 2010. Subduction initiation at passive margin: numerical modeling. J. Geophys. Res. 115, B03406. doi:10.1029/ 2009JB006549.

Prockter, L.M., Head, J.W., Pappalardo, RT., Sullivan, RJ., Clifton, A.E., Giese, B. Wagner, R, Neukum, G., 2002. Morphology of Europan bands at high resolution: a mid-ocean ridge-type rift mechanism. J. Geophys. Res. 107, E5. doi: 10.1029/2000JE001458.

Ranalli, G., 1997. Rheology of the lithosphere in space and time. Geol. Soc. Spec. Pub. 121, 19-37

Regenauer-Lieb, K., Yuen, D.A., Branlund, J., 2001. The initiation of subduction: critically by addition of water? Science $294,578-580$.

Romeo, I., Turcotte, D.L., 2008. Pulsating continents on Venus: an explanation for crustal plateaus and tessera terrains. Earth Planet. Sci. Lett. 276, 85-97.

Ruiz, J., Fernández, C., Gomez-Ortiz, D., Dohm, J.M., López, V., Tejero, R, 2008. Ancient heat flow, crustal thickness, and lithospheric mantle rheology in the Amenthes region, Mars. Earth Planet. Sci. Lett. 270, 1-12.

Schubert, G., Turcotte, D.L., Ison, P., 2001. Mantle Convection in the Earth and Planets. Cambridge University Press, Cambridge 940pp.

Sleep, N.H., 1994. Martian plate tectonics. J. Geophys. Res. 99, 5639-5655. 
Solomatov, V.S 2004. Initiation of subduction by small-scale convection J. Geophys. Res. 109, B01412. doi:10.1029/2003JB002628.

Solomatov, V.S., Moresi, L.N., 1997. Three regimes of mantle convection with nonNewtonian viscosity and stagnant lid convection on the terrestrial planets. Geophys. Res. Lett. 124, 1907-1910.

Strom, RG., malhotra, R, 1to, T., Yoshida, F., Kring, D.A., 2005. The origino $\mathrm{f}$ planetary impactors in the inner Solar System. Science 309, 1847-1850.

Stüwe, K., 2007. Geodynamics of the lithosphere, second ed. Springer, Berlin 493pp.

Sullivan, R, et aI., 1998. Episodic plate separation and fracture infill on the surface of Europa. Nature 391, 371-373.

Taylor, S.R, McLennan, S.M., 2009. Planetary Crusts: Their Composition, Origin and Evolution. Cambridge University Press, Cambridge 378pp.

Thompson, D.A., Bastow, I.D., Helffrich, G., Kendall, J.-M., Wookey, J., Snyder, D.B. Eaton, D.W., 2010. Precambrian crustal evolution: seismic constraints from the Canadian Shield. Earth Planet. Sci. Lett. 297, 655-666.

Toth, J., Gurniss, M., 1998. Dynamics of subduction initiation at preexisting fault zones. J. Geophys. Res. 103, 18,053-18,067.

Turcotte, D.L., 1993. An episodic hypothesis for Venusian tectonics. J. Geophys. Res. 98, 17,061-17,068.
Vlaar, NJ., Wortel, MJ R, 1976. Lithospheric aging, instability and subduction. Tectonophysics 32, 331-351.

Watters, T.R, Johnson, C.L, 2010. Lunar tectonics. In: Watters, T.R, Schultz, R.A. (Eds.), Planetary Tectonics. Cambridge University Press, Cambridge, pp. $121-182$

Watters, T.R, Schultz, R.A., 2010. Introduction. In: Watters, T.R, Schultz, RA. (Eds.), Planetary Tectonics. Cambridge University Press, Cambridge, pp. 1-14.

Watters, T.R, Leuschen, C.J., Plaut, J.J., Picardi, G., Safaeinili, A., Clifford, S.M., Farrell, W.M., Ivanov, A.B., Phillips, R.J., Stofan, E.R, 2006. MARSIS radar sounder evidence of buried basins in the northern lowlands of Mars. Nature 444, 905-908.

Watters, T.R, Solomon, S.C., Robinson, M.S., Head, J.W., André, S.L., Hauck, S.A., Murchie, S.L., 2009. The tectonics of Mercury: the view after MESSENGER's first flyby. Earth Planet. Sci. Lett. 285, 283-296.

Williams, J.P., Ruiz, J., Rosenburg, M.A., Aharonson, •., Phillips, R.J., 2011. Solar insolation driven variations of Mercury's lithospheric strength. J. Geophys. Res. 116, E01008. doi:10.1029/2010JE003655 2011.

Zuber, M.T., Smith, D.E., Lemoine, F.G., Neumann, G.A., 1994. The shape and internal structure of the Moon from Clementine mission. Science 266, 1839-1843. 